University of Nebraska - Lincoln

DigitalCommons@University of Nebraska - Lincoln

\title{
Parenting Factors, Social Skills, and Value Commitments as Precursors to School Failure, Involvement with Deviant Peers, and Delinquent Behavior
}

\author{
Ronald L. Simons \\ lowa State University \\ Les B. Whitbeck \\ University of Nebraska-Lincoln, Iwhitbeck2@unl.edu \\ Rand D. Conger \\ lowa State University \\ Katherine J. Conger \\ lowa State University
}

Follow this and additional works at: https://digitalcommons.unl.edu/sociologyfacpub

Part of the Sociology Commons

Simons, Ronald L.; Whitbeck, Les B.; Conger, Rand D.; and Conger, Katherine J., "Parenting Factors, Social Skills, and Value Commitments as Precursors to School Failure, Involvement with Deviant Peers, and Delinquent Behavior" (1991). Sociology Department, Faculty Publications. 93.

https://digitalcommons.unl.edu/sociologyfacpub/93

This Article is brought to you for free and open access by the Sociology, Department of at DigitalCommons@University of Nebraska - Lincoln. It has been accepted for inclusion in Sociology Department, Faculty Publications by an authorized administrator of DigitalCommons@University of Nebraska - Lincoln. 
Published in Journal of Youth and Adolescence 20:6 (1991), pp. 645-664.

Copyright ( 1991 Plenum Publishing Corporation. Used by permission.

This work was supported by Research Grants DA 05347 from the National Institute on Drug Abuse, MH 43270 from the National Institute of Mental Health, and MCJ 190572 from the Bureau of Maternal and Child Health, Department of Health and Human Services.

\title{
Parenting Factors, Social Skills, and Value Commitments as Precursors to School Failure, Involvement with Deviant Peers, and Delinquent Behavior
}

\author{
Ronald L. Simons, ${ }^{1}$ Les B. Whitbeck, ${ }^{2}$ \\ Rand D. Conger, ${ }^{3}$ and Katherine J. Conger ${ }^{4}$
}

\begin{abstract}
Elements of social control theory were combined with social learning theory to construct a model of delinquency which specifies the manner in which parenting factors, social skills, value commitments, and problems in school contribute to association with deviant peers and involvement in delinquent behavior. The model was tested using a sample of 61 families, each of which included a seventh grader. Questionnaire responses and coded videotaped family interaction were employed as measures of study constructs. The results largely supported the proposed model.
\end{abstract}

1 Professor, Department of Sociology, Iowa State University, Ames, Iowa 50011. Ph.D., Sociology, Florida State University. Research interests include etiology of adolescent depression, substance abuse, and delinquency; identification of factors that influence parenting practices; causes and consequences of adolescent and adult homelessness. To whom correspondence should be addressed.

2 Assistant Professor, Department of Sociology, Iowa State University, Ames, Iowa 50011. Ph.D., Sociology, Washington State University. Research interests include impact of family and peers upon adolescent value socialization, self-esteem, and perceptions of self-efficacy; street culture among adolescent runaways and adult homeless.

3 Professor, Department of Sociology, Iowa State University, Ames, Iowa 50011. Ph.D., Sociology, University of Washington. Research interests include impact of economic stress upon family dynamics, and relationship between parenting practices and adolescent developmental outcomes.

4 Assistant Professor, Department of Child Development and Family Environment, Iowa State University, Ames, Iowa 50011. Doctoral candidate in sociology at Iowa State University. Research interests include economic hardship and marital interaction, and determinants and consequences of variation in sibling interaction. 


\section{Introduction}

A profusion of studies attest to an association between participation in a deviant peer group and involvement in delinquent behavior (Akers et al., 1979; Conger, 1976; Elliott et al., 1985; Jessor and Jessor, 1977; Johnstone, 1981; Kaplan et al., 1984; Meade and Marsden, 1981; Simons et al., 1980). While some have argued that this correlation is a consequence, not a cause, of delinquency (Hirschi, 1969; Kornhauser, 1978), results from panel studies suggest a reciprocal relationship where deviant youth tend to select deviant friends, and involvement with deviant friends serves to escalate participation in deviant behavior (Cohen, 1977; Elliott et al., 1985; Ginsberg and Greeley, 1978; Kandel, 1978). Social control theory, the premiere delinquency theory of the 1980s, must be recast in order to accommodate this finding (Elliott et al., 1985; Krohn and Massey, 1980).

Social control theory maintains that children naturally tend to engage in deviant behavior unless social control mechanisms are present that inhibit its occurrence. Thus delinquency occurs because of weak bonds to conventional norms and groups, and the resulting absence of constraints on deviant behavior (Hirschi, 1969). However, evidence from recent studies indicates that weak bonds to conventional others, e.g., parents, will allow, but not necessarily foster, delinquency (Elliott et al., 1985; Krohn and Massey, 1980). Rather, the motivation to engage in habitual and/or serious deviance is derived from association with deviant peers who model and reinforce delinquent behavior. Such findings are more consistent with a social learning than a strictly social control explanation of adolescent deviance, and they underscore the importance of formulating models that specify the processes whereby youth become involved in a deviant peer group. Building upon the work of Patterson $(1982,1986)$ and incorporating elements of social control theory, Simons et al. (1988) recently presented a social learning model that attempts to explain the mechanisms whereby youth begin to associate with deviant peers. A somewhat simplified version of their explanation is depicted in Figure 1. The present paper provides a test of the model presented in the figure.

Over the last few years, Gerald Patterson (Patterson, 1982, 1986) has emphasized the consequences of an irritable, coercive parenting style. Such an approach to parenting is characterized by explosiveness, nattering, and threats, often coupled with little consistency or follow-through. They posit that such parenting practices are not only ineffective in controlling the child's antisocial behavior (e.g., noncompliance, whining, teasing, hitting, yelling), they have the effect of exacerbating his/her aggressiveness. Irritable, coercive parenting tends to elicit an aggressive response from the child, which in turn increases the negative response of 


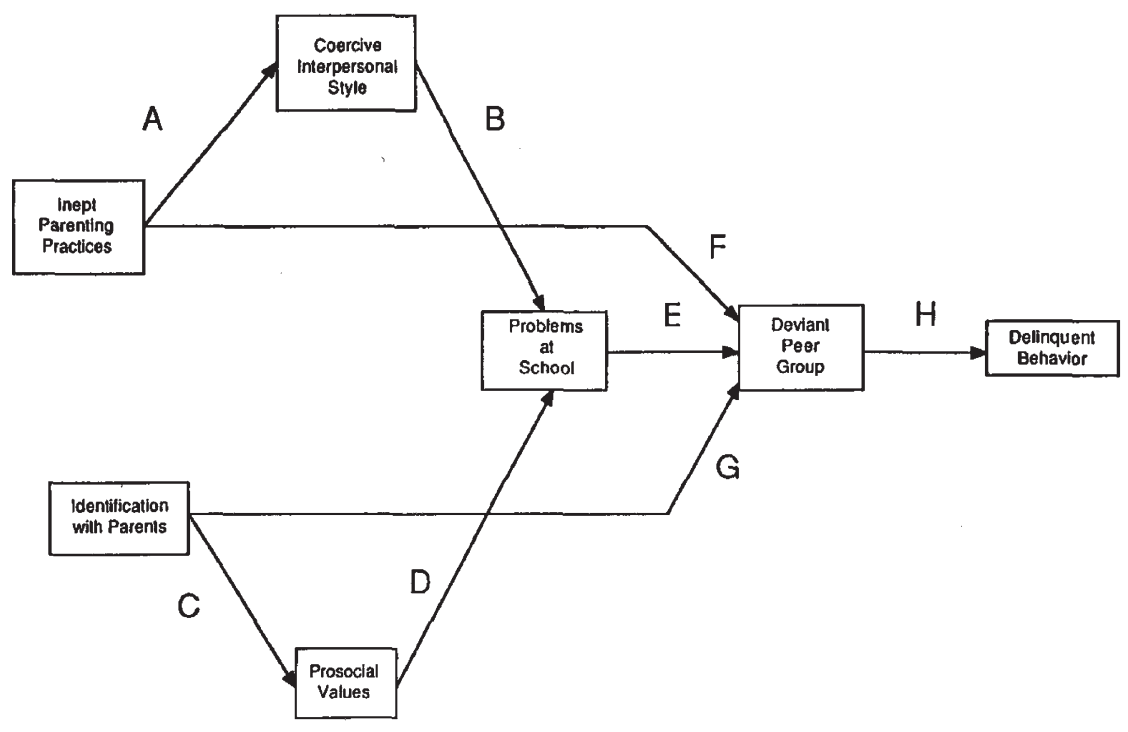

Figure 1. A social learning model of delinquent behavior.

the parent, and so on. Thus, the parent's influence attempts produce coercive spirals where each of the parties uses punishment in an effort to control the behavior of the other. Patterson $(1982,1986)$ finds that children socialized in such an atmosphere learn to use aggressive methods to influence others, while more socially appropriate skills are not modeled and reinforced. This relationship is depicted by Arrow A in Figure 1.

The model goes on to posit that children often generalize this coercive interpersonal style from the family to interactions with peers and teachers at school. Studies by Patterson (1986), as well as by others (Cobb and Hops, 1973; Hops and Cobb, 1974), indicate that aggressive, noncompliant children are often disruptive and off-task, with the result being rejection by teachers and academic failure. Further, these youngsters are frequently involved in fights and altercations on the playground. Thus, a coercive interpersonal style increases the probability that a child will experience academic failure, be disruptive in the classroom, and engage in troublesome behavior on the playground (Arrow B).

Importantly, these difficulties at school are likely to lead to negative labeling and rejection by conventional peers. Several studies show that more socially skilled peers identify such youngsters as selfish and obnoxious, and do not want to associate with them (Dodge, 1983; Coie and Kupersmidt, 1983; Hartup, 1983; Snyder and Brown, 1983). Having been 
rejected by their more socially skilled peers, the model suggests that aggressive youth drift into association with each other. Given their socialization histories, such individuals are accepting of each other's coercive pattern of interaction. Thus, as shown by Arrow E, youngsters who have not learned to be polite, tactful, sensitive, and compromising in their interactions with others, relying instead upon power assertion strategies, end up participating in a peer group with each other (Simons and Robertson, 1989).

Note that no direct effect is posited between a youth's coercive interpersonal style and involvement with deviant peers. Rather, a coercive interpersonal style is expected to have only an indirect effect upon participation in a deviant peer group through the construct problems at school. In the present model, the interpersonal construct is defined as the extent to which the adolescent displays a coercive interpersonal style within the family. Arrow B, as discussed above, posits that this style of interacting is often generalized to interactions with peers and teachers at school. Of course, this relationship is not perfect; some youngsters, largely in response to contingencies applied by teachers and peers, may learn to use a more appropriate interpersonal style when interacting outside the home. The model suggests that such individuals are not at risk for involvement with deviant peers. While irritable/coercive parenting causes a youngster to adopt a coercive style of interacting with family members, this pattern of interaction does not increase the probability of participation in a deviant peer group unless it is generalized to interactions outside of the home, causing difficulties with peers and teachers at school.

Drawing upon social control theory, the model emphasizes the nature of the parent-child relationship in addition to the consequences of inept parenting practices. As Hirschi (1969) notes in his classic formulation of social control theory, "The emotional bond between the parent and child presumably provides the bridge across which pass parental ideas and expectations" (p. 86). Research on modeling shows that individuals are most likely to emulate the actions of persons they hold in high esteem and/or who are potent sources of reinforcement (Bandura, 1977; Parry and Furukawa, 1980). Thus, youth who are attached to or identify with their parents are more apt to be influenced by their parents' beliefs and opinions. As indicated by Arrow C, a positive association is expected between parental attachment and commitment to prosocial values.

Past research has found that delinquents and nondelinquents differ very little in terms of commitment to conventional values (Elliott et al., 1985). Most of these studies have focused either upon occupational and educational aspirations or upon moral beliefs (Buffalo and Rogers, 1971; Hindelang, 1974; Jensen and Rojek, 1980; Jessor and Jessor, 1977; Minor, 
1977; Simons and Gray, 1989). Both groups appear committed to conventional goals and morality (although delinquents often concomitantly endorse deviant values represented by their peer group).

In contrast to previous research, the present study focuses upon prosocial values such as being considerate, helpful, polite, caring, and cooperative. All parents, regardless of their personal value commitments, are likely to value such socialization outcomes for their children. This is apt to be the case if for no other reason than that family life is easier when the child behaves in accordance with these values. Children who are low on parental attachment, and who therefore fail to acquire these value commitments, are likely to experience difficulties at school (Arrow D). Like youth with deficient social skills, youngsters lacking prosocial value commitments are apt to be at risk for playground altercations, and to be disruptive and off-task in the classroom. As a consequence, they are likely to be rejected by teachers and conventional peers, and by default, to drift into associations with deviant peers (Arrow E).

In addition to their indirect effects through problems with peers and teachers at school, the two parenting constructs are hypothesized to have a direct effect on involvement in a deviant peer group. First, as depicted by Arrow F, quality of parenting practices is expected to impact upon an adolescent's peer associations. Consistent with this contention, Patterson and his colleagues have shown that effective monitoring and discipline can affect a youth's access to an affiliation with deviant peers (Patterson and Dishion, 1985; Snyder et al., 1986). Similarly, the nature of the parent-child relationship should also influence an adolescent's friendship choices (Arrow G). Youth who identify strongly with their parents are likely to care about and be responsive to parental opinions regarding peer associations (Conger, 1976; Simons et al., 1988).

Finally, the model indicates that participation in delinquent behavior is a function of association with deviant peers (Arrow $\mathrm{H}$ ). Relatively unrestrained by the opinions of parents, teachers, or conventional peers, these adolescents tend to encourage, model, and reinforce each other's participation in new types of deviant behavior. While many youngsters experiment with minor forms of delinquent behavior in the course of growing up, the model posits that the motivations and techniques associated with more extreme forms of deviance are learned in a deviant peer group (Simons et al., 1988).

Note that the model indicates that parental behavior, social skills, value commitments, and problems at school do not have a direct effect upon delinquency. Rather, it is posited that these constructs only influence participation in delinquent behavior indirectly by effecting the probability that a youth will become involved with deviant peers. Poor parent- 
ing, school problems, lack of prosocial values, and the like do not provide a rationale for sustained participation in delinquent activities. This motivation is acquired through the modeling and reinforcement extant within the deviant peer group.

\section{Methods and Procedures}

\section{Sample}

The sample for the study was drawn in a largely rural Midwestern county containing approximately 26,000 residents, about half of whom live in rural areas. The majority of the metropolitan residents are located in a community of 12,000 that serves as the county seat. The seven junior high schools in the county were used to generate a list of seventh-grade students. This age group was selected as it represents a period of significant developmental adjustments and vulnerabilities (Werner and Smith, 1982). In addition to the stress of puberty, seventh graders are struggling with the social sorting that necessarily takes place as they leave elementary school and strive to establish themselves in the social structure of the junior high school. Given the shifts and realignments in peer relations that is taking place during this period, it would seem to be an ideal time to investigate the extent to which interpersonal style, parenting factors, values, and problems in school are related to the type of peer group that an adolescent joins.

Names were randomly selected from the lists provided by the schools, and telephone calls were employed to screen the families according to the criteria that both biological parents lived in the home and that there was a sibling within four years of the age of the seventh grader. Approximately $40 \%$ of the families met these criteria, and of these families $57 \%$ agreed to participate in the study. The total sample consisted of $61 \mathrm{fam}-$ ilies, each of whom was paid $\$ 130$ for their effort (\$40 to each of the parents; $\$ 25$ to each of the siblings). Complete data on the study variables was available for 57 of these families.

Certainly, the $57 \%$ response rate raises questions concerning the generalizability of the findings. It should be noted, however, that the most frequent reason for not participating was difficulty in finding two evenings when all four family members could be present for data collection. Often samples are biased because low-income families have a higher refusal rate than those with middle incomes. In the present sample, lowincome persons were motivated to participate in order to earn the $\$ 130$. The possibility remains that the most deviant families were less likely to 
participate. While this occurrence cannot be ruled out, its consequence would be to lower the variance for many of the variables (e.g., school problems, delinquency) with the result in most instances being a reduction in the association found between constructs.

In 33 of the families the seventh grader was male, while in 24 the adolescent was female. All of the families were white, and annual income ranged from $\$ 11,000$ to $\$ 117,000$ with a median of $\$ 33,868$. Fathers' education ranged from eighth grade to Ph.D. with a mean of 13.9 years of education, while for mothers the range was from eighth grade to master's degree with a mean of 13.5. Eighty-four percent of the mothers were employed outside the home on a full- or part-time basis. The fathers ranged in age from 31 to 51 years with a median of 40 years; mothers' ages ranged from 30 to 46 years with a median of 38 years. Since families of less than 4 were excluded from the sampling frame, the families in the study were larger on average than what would be expected from a general population survey. Family size ranged from 4 to 8 members with the average being 4.9 .

\section{Procedures}

Data were collected from the families over two evenings. The first night, each of the 4 family members completed a set of questionnaires focusing upon issues such as parenting, psychological adjustment, self-concept, health, social support, deviant behavior, and economic distress. On average it took about two hours to complete these instruments.

The second night focused upon videotaping family interaction. This evening began by having each individual complete a short questionnaire designed to identify issues of concern or that prompted disagreements within the family (e.g., chores, recreation, money, etc.). The family members were then gathered around the dining room table and given a set of cards listing various daily aspects of living. The cards contained questions related to approaches to parenting, performance in school, household chores, and sibling interaction. The family members were asked to discuss among themselves each of the items listed on the cards. In addition, they were asked to discuss the issues and disagreements that they had cited in the questionnaires that they had completed earlier in the evening. The family's interaction around these tasks was videotaped. Project observers coded the videotapes using a series of rating scales developed by Hetherington and Clingempeel (1986) and modified for the current project, plus rating scales developed by the project investigators. 


\section{Measures}

\section{Inept Parenting}

A few years ago, Nisbett and Wilson (1977) presented evidence suggesting that people cannot validly describe the steps associated with higher level cognitive processes (e.g., problem solving, generation of creative ideas). Similarly, it seems likely that individuals do not consciously track and store many of the more routine, repetitive components of social interaction. If this is true, individuals will tend to be poor reporters for much of their habitual interpersonal behavior. Parenting practices fall into this category of behavior. Over time they tend to become routine, habitual responses, and thus one might be skeptical of people's ability to provide valid descriptions of their parenting behaviors. This contention is consistent with the clinical observation that parents and children rarely have clear insight into the repetitive patterns of behavior that characterize their interaction.

For these reasons, four observational indices based upon the coding of videotaped interactions were combined to form a measure of inept parenting. The four indices involved separate ratings of the mother and father regarding the extent to which they were authoritarian, authoritative, coercive, or nattering when interacting with their seventh grader. With the exception of the Nattering Scale that was developed for the project, the observational rating scales were adapted from Hetherington and Clingempeel's (1986) Behavior Rating Scales for Family Interaction. Their coding system contains a series of 5-point scales, with one defined as not at all characteristic and five as highly characteristic. Project observers coded parents' behavior on two separate tasks and the two ratings were then summed to obtain a total score for each of the four measures. Thus the scores for each of the observational measures ranged from 2 to 10 .

The Authoritarian Scale focuses upon the extent to which the parent emphasizes firm limits and controls while providing few reasons and explanations. A premium is placed upon obedience, and discipline is punitive with minimal tolerance for verbal give and take. The Authoritative Scale measures the degree to which the parent communicates well, is consistent in discipline, sets reasonable, well-defined rules and regulations, and encourages mature, independent behavior. The scores for this scale were reverse coded prior to combining them with the other three measures. The Coercive Parenting Scale assesses parental attempts to control the child through threats, power plays, abstinence, or ploys calculated to make the child feel guilty. And last, the Nattering Scale focuses upon the 
extent to which the parent engages in persistent complaining, nagging, or criticism of the child.

The video-recorded interaction tasks used to construct the scales were independently coded by a criterion observer. For each scale, $25 \%$ of the tasks were independently coded by a second (reliability) coder. Analysis showed that in $93.8 \%$ of the cases for fathers and $94.9 \%$ for mothers the two coders either agreed or were within one step of each other on the rating scales. Pearson product moment correlations were calculated between scale scores of the criterion and reliability coders, summed across tasks and across behaviors for each parent, as an additional measure of interobserver agreement. The interobserver correlation was .76 for fathers and .68 for mothers, with an average reliability coefficient of .72 . These levels are within the range of acceptable values and suggest the presence of basic agreement in observational coding (Bakeman and Adamson, 1984; Hartmann, 1977). Additional information concerning the reliability and validity of the observational measures can be found in Lorenz et al. (1989) and Simons et al. (1990).

Mother and father scores on these scales tended to be highly associated. The correlation between the fathers' combined inept parenting score and that of the mothers was .77. Based upon this high degree of correlation, and given that there is little evidence to suggest that mothers and fathers have different effects upon an adolescent's risk for delinquency, the scores for the two parents were summed to form a composite inept parenting score.

\section{Adolescent Coercive Interpersonal Style}

Father and mother responses to 21 items from the Revised Behavior Problem Checklist (Quay and Peterson, 1983) were combined to form a measure of the extent to which an adolescent manifested a coercive, selfcentered interpersonal style. The items focus upon family interaction and ask about behaviors such as uncooperativeness, noncompliance, selfishness, teasing, bullying, showing off, talking back, bragging, fighting, and blaming others for one's problems. Previous research has established the reliability and construct validity of the complete Revised Behavior Problem Checklist (Quay and Peterson, 1983), while coefficient alpha for the selected items used in the present study was .93 for mothers and .90 for fathers. The correlation between mother and father reports was .58.

Consideration was given to constructing observational measures of coercive interpersonal style using the videotapes, but it was concluded that questionnaire scales were preferable for two reasons. First, the vari- 
ance associated with the construct would be limited if an observational measure was employed as adolescents are likely to engage in only superficial acts of opposition, noncompliance, and aggression during videotaped discussions. Second, parents' nattering and coercive discipline during the discussions is likely to take place in response to any noncooperation and aggression on the part of their child, thereby inflating the correlation between the inept parenting construct and the adolescent interpersonal style construct.

\section{Identification with Parents}

This construct was measured by adolescents' responses to 3 items concerned with the extent to which their parents are perceived as attractive role models. The items were adapted from Elliott et al. (1985) and ask the respondents to report whether they want to grow up to be like their mother/father, the extent to which they respect each of their parents, and how much they enjoy spending time with them. Response categories ranged from 1 (strongly disagree) to 5 (strongly agree). Cronbach's alpha was .83 for ratings of fathers and .72 for ratings of mothers. The correlation between the parent ratings was .80 . The ratings for mothers and fathers were summed to obtain a single measure of identification with parents.

\section{Prosocial Values}

Ten items from the Braithwaite and Law (1983) were used to form a measure of prosocial values. The Braithwaite and Law value inventory is derived from the widely used Rokeach Value Survey (1973). It differs from the Rokeach instrument in that it is more extensive and involves rating values rather than ranking them in terms of importance. The items used to form a prosocial measure were selected based upon face validity. The items focused upon value commitments regarding being considerate, helpful, polite, loving, and self-controlled. Response categories ranged from 1 (I very strongly reject this rule or goal) to 7 (I very strongly accept this rule or goal). Coefficient alpha for the scale was .91.

\section{School Problems}

Father, mother, and adolescent self-reports were used to measure the problems in school construct. Unfortunately, teacher ratings and school records could not be obtained. Each of the parents responded to a 5-item 
scale that asked about their child's grade point average, relationships with teachers, completion of homework attendance record, and troubles with school authorities as a result of fighting or other rule infractions. Coefficient alpha was .74 for mothers and .71 for fathers. The adolescents completed a 10-item scale comprised of questions very similar to those asked of the parents. Alpha for this scale was .87. The correlation between mother and father reports was .71, while adolescent self-report correlated .63 and .70 with mother and father reports respectively. As noted, the adolescent instrument was twice as long as the one completed by parents. Therefore, scores on the three measures were converted to $Z$ scores prior to adding them together to obtain a total score. This had the effect of giving each of the three measures an equal weight.

\section{Deviant Peer Group}

Two adolescent self-report indices were used to assess involvement with deviant peers. The first measure asked the respondent to indicate the extent to which he/she agreed or disagreed with five statements concerning their close friends. The statements focused upon breaking the law, getting bad grades, trouble with parents, difficulties at school, and trouble with the police. The response format ranged from 1 (strongly disagree) to 5 (strongly agree). The scale achieved an alpha of .76. A second measure asked respondents to report how many of their close friends had engaged in any of 15 deviant behaviors. The list of deviant acts included items such as skipping school, using alcohol, purposefully destroying property, attacking someone with a weapon, shoplifting, and using or selling drugs. In reporting the number of close friends who participated in these events, the respondent could select from 5 responses ranging from none of them to all of them. An alpha of .85 was obtained for this measure. There was a .64 correlation between the two measures of deviant peer group. $Z$ scores were used in adding the two measures together so as to achieve an equal weighing of the two scales. Parental reports were not used as indicators of deviant peer group as parents were viewed as often lacking accurate information concerning the nature of their adolescent's friends. While parents may be valid sources of data concerning the friends of their children during the elementary school years, they have less access to this information once their child enters junior high school and friendship associations take place away from the home. Consistent with this idea, both father and mother ratings of their child's friends showed low to insignificant associations with the two adolescent self-report measures described above. 


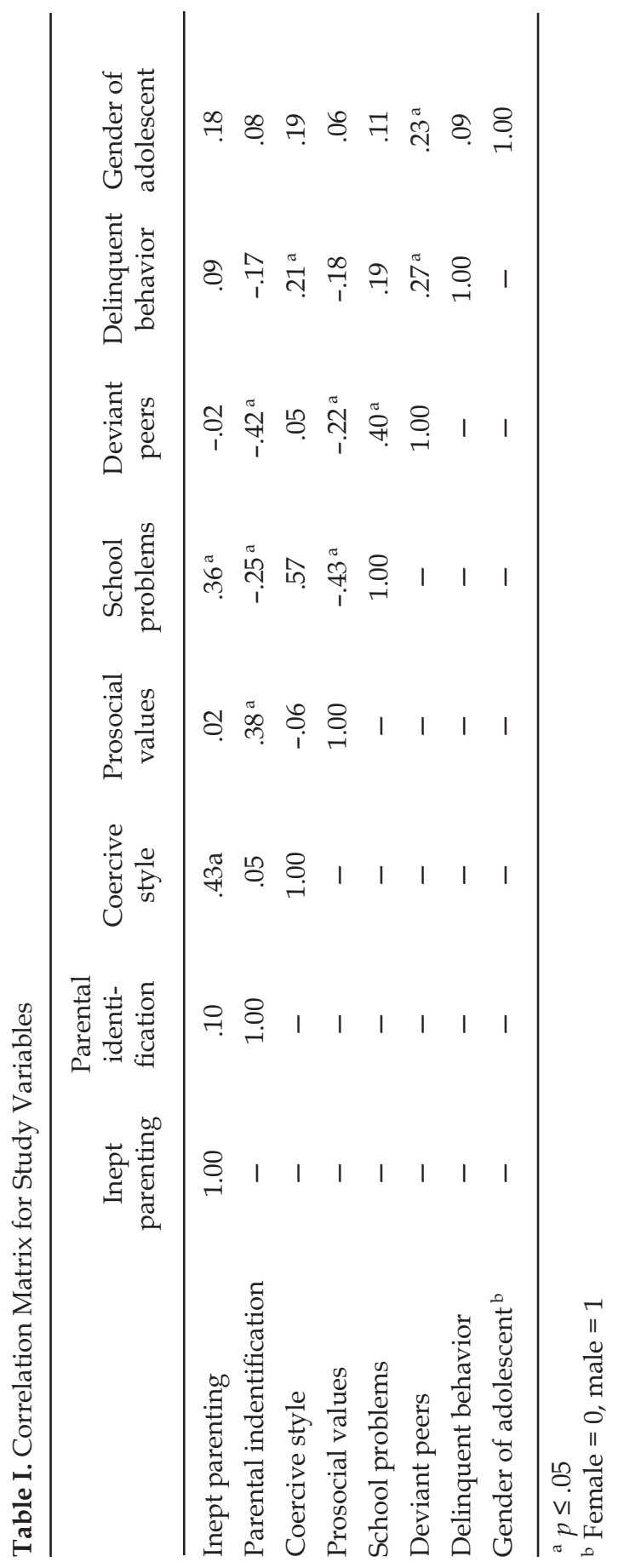




\section{Delinquent Behavior}

A 30-item adolescent self-report index was used to measure delinquency. The index was adapted from the scale developed by Elliott et al. (1985) in their effort to address the criticisms frequently made of earlier measures, e.g., only including trivial offenses, failing to measure frequency (Hindelang et al., 1981; Elliott and Huizinga, 1983). The 30 items that comprise the measure range from rather minor acts, such as running away from home or skipping school, to more serious offenses involving robbery, theft, or the sale of controlled substances. Respondents were asked to report how many times they had committed each of the acts within the last year.

\section{Results}

The mean and standard deviation for each of the study variables are displayed in Appendix A. As expected, the delinquency measure showed less variability than the others, with most of the respondents reporting little involvement in deviant behavior. Some of the seventh graders did, however, report more frequent participation in deviant acts. For example, $15 \%$ of the respondents scored five or higher on the measure and $6 \%$ had scores of over nine. Given the skewed nature of the distribution, a square root transformation was performed on this variable prior to performing the correlational and multivariate analysis. Such a transformation has the effect of reducing the extent to which coefficients are influenced by a few extreme scores.

The correlation matrix for the variables is presented in Table I. The zero-order correlations are largely consistent with the hypothesized model. Given the limited sample size, the multivariate test of the model utilized ordinary least squares rather than latent variable approaches to structural equation modeling (e.g., LISREL), which would capitalize on the multiple measure component of some of the constructs. The rather small sample also precluded performing path analysis by gender. While the correlations were sometimes larger for one sex compared to the other, the signs of the relationships tended to be consistent across gender. This is consonant with previous studies reporting that parallel processes operate in the etiology of male and female delinquency (Simons et al., 1980).

Albeit, to further test for gender effects, sex of respondent and the interaction terms created by multiplying gender by each of the independent variables were entered into the regression equations at each step of the path analysis. Including gender ruled out the chance that some of the 


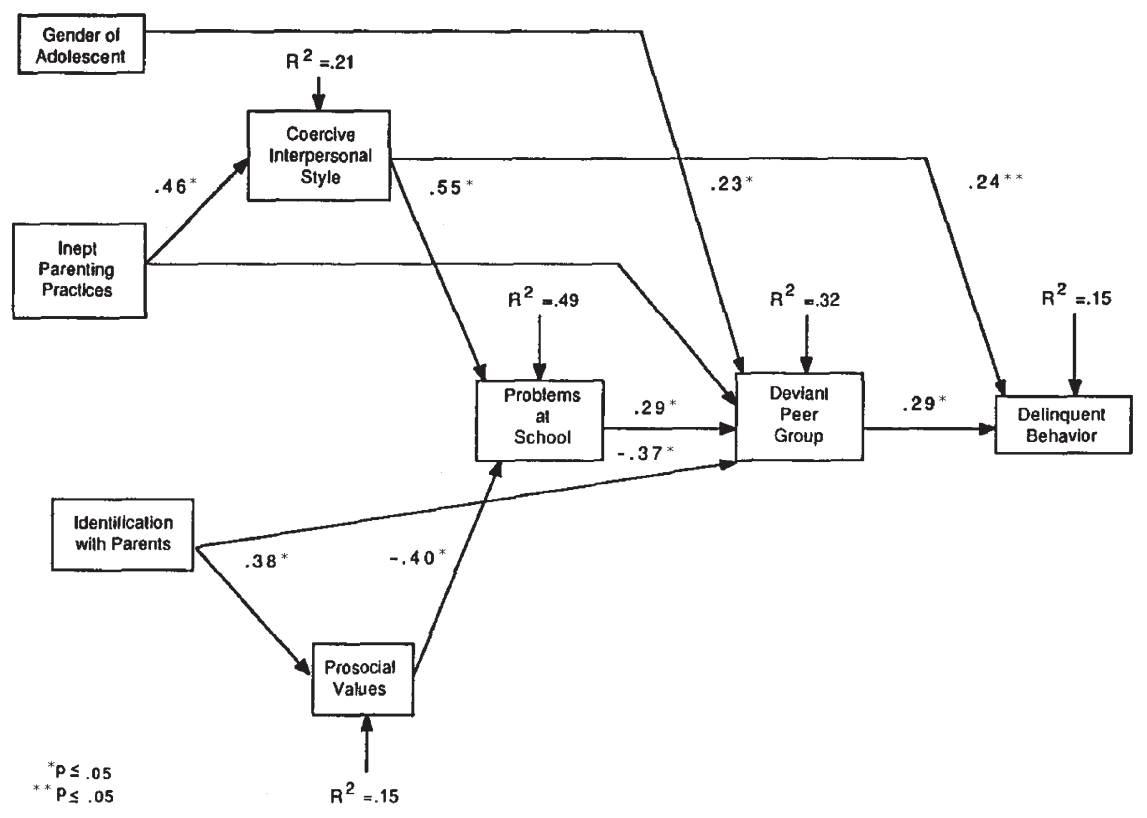

Figure 2. Results of path analysis.

findings might be spurious due to sex, while incorporating the interaction terms tested for the possibility that the impact of some of the variables differed by gender.

An iterative process was employed in performing the path analysis. First, the fully recursive model was calculated. Insignificant variables were then deleted one at a time and the regression equations reanalyzed until the equation for each step contained only constructs significant at the .10 level or less.

The path coefficients for the reduced model are presented in Figure 2. The results largely support the hypothesized model. The construct inept parenting practices is strongly related to coercive interpersonal style $(\beta=$ .46), while identification with parents is associated with prosocial value commitments $(\beta=.38)$. A coercive interpersonal style and prosocial values are, in turn, predictors of problems at school $(\beta=.55$ and -.40 , respectively). Indeed, together these two variables account for half of the variance in school problems.

As predicted, both identification with parents $(\beta=-.37)$ and problems at school $(\beta=.29)$ are associated with involvement in a deviant peer group. Albeit, contrary to expectation, inept parenting is not related to association with deviant peers. Gender only shows a significant effect for the vari- 
able peer group. The coefficient of .23 indicates that males are more likely than females to associate with deviant peers. None of the interaction terms formed with the variable gender demonstrated a significant effect. The three variables identification with parents, problems at school, and gender explain about one third of the variance in peer group affiliation.

Finally, as expected, involvement with deviant peers is associated with participation in delinquent behavior $(\beta=.29)$. The model posited that family factors, values, social skills, and problems at school would only influence delinquency indirectly through their impact upon choice of peers. While this is true for most of these variables, coercive interpersonal style shows a direct effect upon delinquency. In addition to its indirect influence upon delinquency through problems at school and involvement with deviant peers, having a coercive interpersonal style impacts directly upon the probability of participation in delinquent behavior $(\beta=.24)$.

\section{Discussion}

A profusion of studies have reported that parenting factors (both parenting practices and the quality of the parent-child relationship; Loeber and Stouthamer-Loeber, 1986; Snyder and Patterson, 1987), level of social skill development, especially an aggressive interpersonal style (Loeber and Dishion, 1983; Olweus, 1979), problems at school (Hawkins and Lam, 1987; Spivack and Cianci, 1987), association with deviant peers (Elliott et al., 1985; Simons et al., 1988), and to a lesser degree, lack of commitment to conventional values (Elliott et al., 1985) are related to involvement in delinquent behavior. The present study tested a model that attempts to specify the interrelationships and causal sequences operating among these variables.

The model suggests that adolescents who are subjected to inept parenting practices (nattering, authoritarian, minimal explanation) tend to develop a coercive interpersonal style and that youngsters who do not identify with their parents often fail to develop prosocial value commitments. It was posited that these two socialization outcomes, in turn, put youth at risk for difficulties with course work, teachers, and conventional peers at school. The findings strongly corroborated this set of hypotheses. Indeed, these variables accounted for half of the variance in school problems.

Although no relationship was posited as part of the social learning model, it is interesting to note that there was no association between the two exogenous variables of inept parenting and parental identification. This finding suggests that utilization of effective parenting techniques has little or no impact upon the probability that youngsters will select their parents as role models. Perhaps it is the affective quality of the par- 
ent-child relationship (viz., nurturant vs. rejecting), rather than the parenting practices included in the present study, which serve to foster an adolescent's identification with parents.

Academic problems and rejection by teachers and conventional peers were expected to have the consequence of encouraging drift into a deviant peer group. As noted above, several studies have reported an association between difficulties at school and delinquent behavior (see Hawkins and Lam, 1987; Spivack and Cianci, 1987). One rather popular explanation for this relationship is that youth who fail in school strive to increase their self-esteem by flouting conventional norms and engaging in deviant acts (Kaplan, 1980). This explanation is problematic, however, as several panel studies have failed to find a relationship between self-esteem and delinquency (McCarthy and Hoge, 1984; Wells and Rankin, 1983). The present model offers a different explanation. It suggests that a coercive interpersonal style causes youngsters to experience difficulties with peers and authority figures at school, and that these difficulties lead to negative labeling and rejection by conventional peers. This suggests that problems at school do not have a direct effect upon delinquency, but contribute indirectly to such behavior by increasing the probability of association with deviant peers. Thus the model predicts that controlling for the construct deviant peers would eliminate the association between school problems and delinquency. The results were consistent with this expectation.

In addition to school problems, parenting factors were also expected to influence the probability of involvement with deviant peers. The results only partially supported this hypothesis. Identification with parents lowered the risk of such involvements but, contrary to expectation, the variable parenting practices was not related to association with deviant peers. Perhaps this finding should come as no surprise given, as indicated in the measurement section, the small correlation between adolescent self-report and parent ratings of peer associations. Parents cannot effectively discourage involvement with deviant peers if they lack accurate information concerning the conduct of their child's friends. It should also be noted that while the results suggest that the parenting practices included in the present study (i.e., the parent's approach to training and correcting the child) are not important determinants of a youth's involvement in a deviant peer group, it may be that other parenting practices, such as effective monitoring and supervision (Conger, 1976; Hirschi, 1969; Patterson, 1982, 1986), function to reduce the probability of association with deviant peers.

Finally, the model predicted that the effects of all of the prior variables upon delinquency would be mediated through association with deviant peers. It was argued that while many youngsters may experiment with minor forms of delinquent behavior in the course of growing up, 
the motivations and techniques associated with frequent and/or extreme deviance are acquired through participation in a deviant peer group. This contention was largely supported. Parenting factors, prosocial value commitments, and problems at school only impacted delinquency indirectly through their influence upon type of peer group. Contrary to expectation, however, the presence of a coercive interpersonal style directly increased the probability of involvement in delinquency regardless of the nature of peer associations.

Prior studies have established that children who display aggressive behavior during the early elementary grades are at risk for delinquency during adolescence (Loeber and Dishion, 1983; Olweus, 1979). The social learning model tested in the present study posited that such behavior is caused by inept parenting, and that it leads to delinquency because it produces difficulties at school and drift into a deviant peer group. While the results supported this argument, the findings also indicate that a coercive interpersonal style increases involvement in delinquent behavior independent of peer influences. It seems that adolescents who are noncompliant and aggressive within the context of the family are likely to flout the norms and laws of the larger society as well, regardless of whether such behavior is modeled and reinforced by peers.

Although the findings of the study largely support the proposed social learning model, the data are also consistent with alternative causal arguments. Some have contended, for example, that involvement in a deviant peer group is a consequence, not a cause, of delinquency (Hirschi, 1969; Kornhauser, 1978). And the correlation between inept parenting and an adolescent's social skills might be taken as an indication that aggressive, noncompliant youth disrupt normal parenting practices. While cross-sectional data precludes resolution of issues of causal ordering, it should be noted that findings from panel studies support the contention that involvement with deviant friends serves to escalate participation in delinquent behavior (Cohen, 1977; Elliott et al., 1985; Ginsberg and Greenley, 1978; Kandel, 1978). And the results of at least one longitudinal study indicate that causal priority is from ineffective parenting to adolescent problem behavior, rather than from problem behavior to ineffective parenting (Simons et al., 1989).

The generalizability of the results are limited by the fact that the study sample consisted of rural and small-town families. There is reason to believe, however, that the results are likely to hold for urban residents as well. Other studies have found that, while the magnitude of associations may differ slightly, the same variables tend to predict delinquency in both rural and urban areas (Gardner and Shoemaker, 1989; Lyerly and Skipper, 1981). And the results of the present study are consistent with the findings of studies by Patterson (1989) using urban samples. 


\section{References}

Akers, R. L., Krihn, M. D., Lanza-Kanduce, L., and Radosevich, M. J. (1979). Social learning and deviant behavior: A specific test of a general theory. Am. Social. Rev. 44: 636-655.

Bakeman, R., and Adamson, L. B. (1984). Coordinating attention to people and objects in mother-infant and peer-infant interaction. Child Develop. 55: 1278-1289.

Bandura, A. (1977). Social Learning Theory. Prentice-Hall, Englewood Cliffs, NJ.

Buffalo, M. D., and Rogers, J. W. (1971). Behavioral norms, moral norms, and attachment: Problems of deviance and conformity. Social Prob. 19: 101-113.

Coie, J. D., and Kupersmidt, J. B. (1983). A behavioral analysis of emerging social status in boys' groups. Child Develop. 54: 1400-1416.

Cohen, J. M. (1977). Sources of peer group homogeneity. Social. Educat. 50: 227-241.

Conger, R. D. (1976). Social control and social learning models of delinquent behavior. Criminology 14: 17-40.

Dodge, K. A. (1983). Behavioral antecedents of peer social status. Child Develop. 54: 1386- 1399.

Elliott, D. S., and Huizinga, D. (1983). Social class and delinquent behavior in a national youth panel. Criminology 21: 149-177.

Elliott, D. S., Huizinga, D., and Ageton, S. S. (1985). Explaining Delinquency and Drug Use. Sage, Beverly Hills, CA.

Ginsberg, I. J., and Greenley, J. R, (1978). Competing theories of marijuana use: A longitudinal study. J. Health Social Behav. 19: 22-34.

Hartmann, D. P. (1977). Considerations in the choice of interobserver estimates. J. Appl. Behav. Anal 10: 103-119.

Hartup, W. W. (1983). Peer relations. In Mussen, P. (ed.), Handbook of Child Psychology: Vol. IV. Socialization, Personality, and Social Development. Wiley, New York.

Hawkins, J. D., and Lain, T. (1987), Teacher practices, social development, and delinquency. In Burchard, J. D. and Burchard, S. N. (eds.), Prevention of Delinquent Behavior. Sage, Beverly Hills, CA.

Hetherington, E. M., and Clingempeel, G. (1986). Global Coding Manual. Department of Psychology, University of Virginia, Charlottesville, VA.

Hindelang, M. J. (1974). Moral evaluations of illegal behaviors. Social Prob. 21: 370-385.

Hindelang, M. J., Hirschi, R., and Weis, J. G. (1981). Measuring Delinquency. Sage, Beverly Hills, CA.

Hirschi, T. (1969). Causes of Delinquency. University of California Press, Berkeley, CA.

Hops, H., and Cobb, J. A. (1974). Initial investigations into academic survival-skills training: Direct instruction and first grade achievement. J. Educat. Psychol. 66: 548-553.

Jensen, G. F., and Rojek, D. G. (1980). Delinquency, A Sociological View. D. C. Heath, Lexington, MA.

Jessor, R., and Jessor, S. L. (1977). Problem Behavior and Psychosocial Development: A Longitudinal Study of Youth. Academic, New York.

Johnstone, J. W. C. (1981). The family and delinquency: A reappraisal. In Meade, A. C. (ed.), Youth and Society: Studies of Adolescent Deviance. Institute for Juvenile Research, Chicago.

Joreskog, K. G., and Sorbom, D. (1986). LISREL VI-Analysis of Structural Relationships by 
the Method of Maximum Likelihood (4th ed.). Scientific Software, Mooresville, IN.

Kandel, D. B. (1978). Homophily, selection and socialization in adolescent friendships. Am. J. Sociol. 84: 427-436.

Kaplan, H. B. (1980). Deviant Behavior in Defense of Self. New York.

Kaplan, H. B., Martin, S. S., and Robbins, C. (1984). Pathways to adolescent drug use: Self-derogation, peer influence, weakening of social controls, and early substance use. J. Health Social Behav. 25: 270-288.

Kornhauser, R. R. (1978). Social Sources of Delinquency. University of Chicago Press, Chicago.

Krohn, M. D., and Massey, J. L. (1980). Social control and delinquent behavior: An examination of the elements of the social bond. Sociol. Quart. 21: 529-543.

LeGrande, G., and Shoemaker, D. J. (1989). Social bonding and delinquency: A comparative analysis. Sociol. Quart. 30: 481-499.

Loeber, R., and Dishion, T. (1983). Early predictions of male delinquency: A review. Psychol. Bull. 93: 68-99.

Loeber, R., and Stouthamer-Loeber, M. (1986). Family factors as correlates and predictors of juvenile conduct problems and delinquency. In Tory, M., and Morris, N. (eds.), Crime and Justice: An Annual Review (Vol. 7). University of Chicago Press, Chicago.

Lorenz, F. O., Conger, R. D., Simons, R. L., and Elder, G. H. (1989). Economic strain and marital quality: An illustration of method variance problems in causal modeling. Paper presented at the meeting of National Council on Family Relations, New Orleans, LA.

Lyerly, R. R., and Skipper, J. K., Jr. (1981). Differential rates of rural-urban delinquency: A social control approach. Criminology 19: 385-399.

McCarthy, J. D., and Hoge, D. R. (1984). The dynamics of self-esteem and delinquency. Am. J. Sociol. 90: 396-410.

Meade, A. C., and Marsden, M. E. (1981). An integration of classic theories of delinquency. In Meade, A. C. (ed.), Youth and Society: Studies of Adolescent Deviance. Institute for Juvenile Research, Chicago.

Minor, W. W. (1981). Techniques of neutralization: A reconceptualization and empirical examination. J. Res. Crime Delinq. 18: 295-318.

Nisbett, R. E., and Wilson, T. D. (1977). Telling more than we can know: Verbal reports on mental processes. Psychol. Rev. 84: 231-259.

Olweus, D. (1979). Stability of aggressive reaction patterns in males: A review. Psychol. Bull. 86: 852-857.

Parry, M. A., and Furukawa, M. J. (1980). Modeling methods. In Kanfer, F. H. and Goldstein, A. P. (eds.), Helping People Change (2nd ed.). Pergamon, New York.

Patterson, G. E. (1982). Coercive Family Process. Castalia, Eugene, OR.

Patterson, G. E. (1986). Performance models for antisocial boys. Am. Psychol. 41: 432-444.

Patterson, G. E., and Dishion, T. J. (1985). Contribution of families and peers to delinquency. Criminology 23: 63-79.

Quay, H. C., and Peterson, D. R. (1983). Interim Manual for the Revised Behavior Problem Checklist. University of Miami, Miami, FL.

Simons, R. L., and Gray, P. A. (1989). Perceived blocked opportunity as an explanation of delinquency among lower class black males: A research note. J. Res. Crime Delinq. 26: 90-101.

Simons, R. L., Conger, R. D., and Whitbeck, L. B. (1988). A multistage social learning 
model of the influences of family and peers upon adolescent substance use. J. Drug Issues 18: 293-316.

Simons, R. L., Miller, M. G., and Aigner, S. M. (1980). Female delinquency and the traditional theories of deviance: An empirical test. J. Res. Crime Delinq. 17: 42-57.

Simons, R. L., and Robertson, J. F. (1989). The importance of parenting factors, deviant peers, and coping style in the etiology of adolescent substance use. Family Relat. 38: 273-281.

Simons, R. L., Robertson, J. F., and Downs, W. R. (1989). The nature of the association between parental rejection and delinquent behavior. J. Youth Adolesc. 18: 297-310.

Simons, R. L., Whitbeck, L. B., Conger, R. D., and Melby, J. N. (1990). Husband and wife differences in determinants of parenting: A social learning/exchange model of parental behavior. J. Marriage Family, 52: 375-392.

Snyder, J. J., and Brown, K. (1983). Oppositional behavior and noncompetence in preschool children: Environmental correlates and skill deficits. Behav. Assess 5: 333-348.

Snyder, J. J., and Patterson,. G. R. (1987). Family interaction and delinquent behavior. In Quay, H. C. (ed.), Handbook of Juvenile Delinquency. Wiley, New York.

Snyder, J. J., Dishion, T., and Patterson, G. R. (1986). Determinants and consequences of associating with deviant peers during preadolescence and adolescence. J. Early Adolesc. 6: 29-43.

Spivack, G., and Cianci, N. (1987). High-risk early behavior pattern and later delinquency. In Burchard, J. D. and Burchard, S. N. (eds.), Prevention of Delinquent Behavior. Sage, Beverly Hills, CA.

Wells, L. E., and Rankin, J. H. (1983). Self-concept as mediating factor in delinquency. Social Psychol Quart. 46: 11-22.

Appendix A. Distributions for Study Variables $(N=57)$

\begin{tabular}{lcc}
\hline & Mean & $\begin{array}{c}\text { Standard } \\
\text { deviation }\end{array}$ \\
\hline Inept parenting & 40.05 & 10.48 \\
Parental identification & 10.37 & 3.80 \\
School problems & $.07^{\mathrm{a}}$ & 1.70 \\
Deviant peers & $-.18^{\mathrm{a}}$ & 1.71 \\
Prosocial values & 54.89 & 7.20 \\
Coercive style & 16.00 & 11.96 \\
Delinquent behavior & 1.60 & 2.85 \\
\hline
\end{tabular}

a Scale formed by adding Z scores for two or more measures. 